\title{
KOMPARASI PERASAAN KELELAHAN KERJA PADA SHIFT KERJA YANG BERBEDA DI DEPARTEMEN FORMING PT. ROYAL KORINDAH PURBALINGGA TAHUN 2017
}

\author{
Tita Dede Hari Fitroh Nurjanah*), Yulianto ${ }^{* *}$ ) \\ Jurusan Kesehatan Lingkungan, Politeknik Kesehatan Kemenkes Semarang, \\ Jl.Raya Baturaden KM 12 Purwokerto, Indonesia (10pt Normal Italic)
}

\begin{abstract}
Abstrak
Perasaan kelelahan kerja adalah gejala subyektif lelah pada pekerja yang mengalami kelelahan kerja, yang merupakan semua perasaan yang tidak menyenangkan. Tujuan dari penelitian ini adalah untuk mengetahui perbedaan perasaan kelelahan kerja pada shift kerja yang berbeda di Departemen Forming PT. Royal Korindah Purbalingga. Metode penelitian yang digunakan yaitu pendekatan cross sectional. Analisis menggunakan uji kruskal wallis. Sampel yang diambil sebanyak 74 tenaga kerja sebagai responden. Pengambilan data dengan pengisian angket kuesioner alat ukur perasaan kelelahan kerja (KAUPKK). Hasil penelitian ini yaitu tidak ada perbedaan perasaan kelelahan kerja pada shift kerja yang berbeda di Departemen Forming PT. Royal Korindah Purbalingga. Hasil uji statistik menunjukan bahwa nilai assympt sign adalah 0,687 lebih besar dari nilai $\alpha=0,05$. Hasil pengukuran perasaan kelelahan kerja yaitu 18 tenaga kerja mengalami kelelahan sangat ringan, 34 tenaga kerja mengalami kelelahan ringan, 18 tenaga kerja mengalami kelelahan agak berat dan 4 tenaga kerja mengalami kelelahan berat.Berdasarkan hasil tersebut dapat disimpulkan bahwa tidak ada perbedaan perasaan kelelahan kerja pada shift kerja yang berbeda di Departemen Forming PT. Royal Korindah Purbalingga. Saran untuk pihak perusahaan yaitu monitoring rutin terhadap lingkungan kerja dan memberikan waktu istirahat pendek setelah 4 jam melakukan kerja.
\end{abstract}

Kata kunci:perasaan kelelahan kerja; shift kerja;kesehatanlingkungan

\begin{abstract}
[Comparison Feeling of Work Fatigue on Different Work Shift in Forming Departement pt. Royal KorindahPurbalingga Year of 2017]Feeling of work fatigue is symptoms of subjective tired of workers who are tired of work, which is all an unpleasant feeling.the purpose of this research is to know the difference feeling of work fatigue at different work shift in forming departement of PT. Royal korindah Purbalingga. The research method used cross sectional approach. Data analysis use kruskal wallis test. The samples which taken as many as 74 workers as respondents. Data collection by charging inquiry using questionnaire measuring the feeling of work fatigue. The result of this research is there is no difference feeling of work fatigue at different work shift in forming departement of PT. Royal Korindah Purbalingga. The results of statistical test show that asympt sign value is 0.687 greater than the value of $\alpha$ $=0.05$. The result of measurement feeling of work fatigue that is 18 workers have very light fatigue, 34 workers have mild fatigue, 18 workers were slightly exhausted and 4 workers have severe fatigue. Based on these results it could be concluded that there no difference in feeling of work fatigue in different work shift in forming departement of PT. Royal Korindah Purbalingga. Suggestions for company are routine monitoring of the work enviroment and provide short rest periods after 4 hours work activity.
\end{abstract}

Keywords:feeling of work fatigue; work shift;environmenthal health

\section{Pendahuluan}

Undang-undang No. 13 tahun 2003, menyatakan bahwa tenaga kerja mempunyai peranan dan kedudukan yang sangat penting sebagai pelaku dan tujuan

\footnotetext{
${ }^{*}$ E-mail: thafinu@gmail.com

${ }^{* *}$ E-mail: yulianto_61@yahoo.com
}

pembangunan, sehingga tenaga kerja memerlukan adanya suatu perlindungan. Perlindungan terhadap tenaga kerja dimaksudkan untuk menjamin hak-hak 
dasar pekerja seperti jaminan tentang keselamatan dan kesehatan kerja.

Upaya kesehatan kerja ditujukan untuk melindungi pekerja agar hidup sehat dan terbebas dari gangguan kesehatan serta pengaruh buruk yang diakibatkan oleh pekerjaan (UU No. 36 tahun 2009 tentang kesehatan pasal 164 ayat 1). Tujuan dari kesehatan kerja adalah yaitu menciptakan tenaga kerja yang sehat dan produktif, tujuan ini dapat tercapai apabila didukung oleh lingkungan kerja yang memenuhi syarat-syarat kesehatan.

Kelelahan kerja dapat menimbulkan beberapa keadaan yaitu keadaan yaitu prestasi kerja yang menurun, fungsi fisiologis motorik dan neural yang menurun, badan terasa tidak enak disamping semangat kerja yang menurun. Perasaan kelelahan kerja cenderung meningkatkan terjadinya kecelakaan kerja, sehingga dapat merugikan diri pekerja sendiri maupun perusahaan karena adanya penurunan produktivitas kerja. Kelelahan kerja terbukti memberikan kontribusi lebih dari 50\% dalam kejadian kecelakaan kerja di tempat kerja.

Penggunaansumberdayasecara optimal dalamrangkameningkatkanproduksidituntutolehduniaind ustrisejakbeberapatahun yang lalu. Hal inimemberikankonsekuensiterhadapperpanjangan jam kerjapekerjadansalahsatunyaadalahdenganmempekerjak anpekerjamelampauiwaktu yang telahditetapkandanataumemberlakukanshiftkerja.

Shiftkerjaadalahsemuapengaturan jam kerja, sebagaipenggantiatausebagautambahankerjapagidansian gharisebagaimana yang biasadilakukan.

Pengaruhshiftkerjaterhadaptubuhantaralainadalah shiftkerjamempengaruhikapasitas mental. Johnson dalamPulat 1992 melaporkanbahwakapasitas mental menurun,

kewaspadaandalambekerjaberkurangmisalnyakejadianpa daquality controldanpengawasan lain. Lebihlanjut Kelly danScheneiderdalamPulat 1992, mengutarakanbahwaterjadikesalahan yang $\begin{array}{llll}\text { meningkatsecarabermaknayaitu } \quad 80 & \text { hingga } & 180\end{array}$ persenpadapelaksanaanshift kerja yang panjang.

PT. Royal Korindah merupakan perusahaan yang bergerak dalam bidang produksi bulu mata palsu dan terletak di Jl. Banjarsari Kembaran Kulon Kabupaten Purbalingga. Selain memproduksi bulu mata palsu, PT. Royal Korindah juga memproduksi platform di Departemen Forming. Dari beberapa bagian produksi di PT. Royal Korindah yang terdapat pembagian shift kerja hanya di Departemen Forming dengan pembagian tiga shift kerja. Departemen Forming merupakan bagian proses pembuatan platform atau wadah yang digunakan untuk membungkus bulu mata palsu yang telah diproduksi. Tujuan dari penelitian ini adalah untuk mengetahui perbedaan perasaan kelelahan kerja pada shift kerja yang berbeda di Departemen Forming PT. Royal Korindah Purbalingga Tahun 2017.

\section{Bahan dan Metode}

Penelitian ini merupakan survei observasi analitik dengan pendekatan cross sectional. Lokasi penelitian ini dilakukan di Departemen Forming PT. Royal Korindah Jl. Banjarsari Kembaran Kulon Kabupaten Purbalingga.

Populasi dalam penelitian ini adalah seluruh pekerja Departemen Forming shift pagi yang berjumlah 138 orang, pekerja shift siang 72 orang dan pekerja shift malam 72 orang.

Pengambilan sampel dalam penelitian ini menggunakan rumus besar sampel yaitudengan keterangan $\mathrm{N}$ adalah jumlah populasi keseluruhan shift kerja yaitu 282 tenaga kerja, dan d adalah presisi absolut $(0,05)$ dan didapatkan hasil besar sampel keseluruhan shift adalah 74 tenaga kerja. Lalu dihitung menggunakan rumus yang sama dengan $\mathrm{N}$ untuk shift pagi 138, N untuk shift siang 72 dan $\mathrm{N}$ untuk shift malam sebanyak 72. Hasil besar sampel shift pagi sebanyak 36 tenaga kerja , shift siang 19 tenaga kerja dan shift malam 19 tenaga kerja.

Pengukuran perasaan kelelahan kerja tenaga kerja Departemen Forming menggunakan Kuesioner Alat Ukur Perasaan Kelelahan Kerja (KAUPKK), sedangkan data karakteristik responden, jenis kelamin, usia, status gizi, jam kerja dilakukan dengan pengisian angket kuesioner yang di isi oleh responden.

Analisis data penelitian dilakukan secara univariat dan multivariat. Analisis univariat dilakukan untuk menggambarkan atau mendeskripsikan dari masing-masing variabel. Analisis multivariat dilakukan dengan menggunakan uji Anova untuk mengetahui perbedaan perasaan kelelahan kerja antara shift pagi, siang dan malam. Namun apabila pada uji Anova hasil uji homogenitas kurang dari 0,05 maka uji Anova diganti menggunakan uji Kruskall Wallis. Apabila hasil uji signifikan maka dilanjutkan dengan analisis bivariat dengan menggunakan t-test untuk mengetahui perbedaan perasaan kelelahan kerja antara shift pagi dengan siang, shift siang dengan malam, dan shift malam dengan pagi.

\section{Hasil dan Pembahasan}

a.Gambaran umum perusahaan PT. Royal Korindah

PT. Royal Korindah terletak di pusat Kota Purbalingga $\pm 21 \mathrm{Km}$ dari Kota Purwokerto, tepatnya di Jalan Banjarsari, Kembaran Kulon, Kecamatan Purbalingga.PT ROYAL KORINDAH adalah perusahaan industri bulu mata dan kuas kosmetik yang berdiri sejak 1976 dengan status PMA berlokasi di Kabupaten Purbalingga, Jawa Tengah. Jumlah karyawan saat ini mencapai 4000 orang lebih dan mitra kerja tersebar di 50 desa/kecamatan.Hasil produksi telah dipasarkan ke berbagai negara di benua Amerika, Eropa, Australia, Timur Tengah dan Asia dengan kapasitas produksi 2.500.000 pasang per bulan dan lebih dari 6000 desain bulu mata telah diproduksi dan dipasarkan. 
Berdasarkan hasil pengamatan di PT. Royal Koridah, dilihat dari segi lokasi PT. Royal Korindah sudah sangat strategis dan menguntungkan dalam menunjang kegiatan operasionalnya karena letaknya yang strategis dan dekat dengan jalan raya. Dengan demikian, akan mempermudah dalam hal transportasi dalam pengadaan bahan baku maupun pengiriman bahan jadi. PT. Royal Korindah beralamat di jalan Banjarsari Kembaran Kulon Kabupaten Purbalingga.

Waktu kerja yang diberlakukan di Departemen Forming dibagi menjadi 3 shift kerja yaitu shift pagi, shift siang dan shift malam. Shift pagi dimulai jam 07.00 - 15.00 WIB dengan waktu istirahat jam $12.00-13.00$ WIB. Shift siang dimulai jam 15.00 - 23.00 WIB dengan waktu istirahat jam 18.00 - 19.00 WIB. Shift malam dimulai dari jam 23.00 - 07.00 WIB dengan waktu istirahat $04.30-05.30 \mathrm{WIB}$.

Proses produksi platform pada Departemen

Forming PT. Royal Korindah yaitu :

1) Cetak

Terdapat 2 model pencetakan yaitu model vacuum dan model automanual. Bahan produksi berupa plastik atau pvc dicetak menggunakan casting.

2) Potong Panjang atau Pendek

Setelah dilakukan proses pencetakan bahan plastik atau pvc yang sudah dicetak lalu di potong sesuai lajur (perlajur) panjang atau pendek.

3) Potong Cutting

Setelah dipotong perlajur panjang atau pendek lalu dilakukan pemotongan per pcs.

4) Printing atau Stamping

Apabila terdapat permintaan untuk pencetakan atau stamp merk, maka dilakukan pencetakan atau stamp merk.

5) Finishing

Pengecekan quantity dan quality sesuai dengan sampel. Setelah finishing lalu dilakukan tranfer penyimpanan ke gudang.

\section{b. Karakteristik tenaga kerja Departemen Forming}

Jumlah tenaga kerja keseluruhan pada PT. Royal Korindah sebanyak 4.944 tenaga kerja, sedangkan jumlah tenaga kerja pada Departemen Forming yaitu 138 tenaga kerja pada shift kerja pagi, 72 tenaga kerja pada shift kerja siang dan 72 orang pada shift kerja malam. Dengan pengambilan sampel yaitu 36 tenaga kerja pada shift pagi, 19 tenaga kerja pada shift siang dan 19 tenaga kerja pada shift malam.

Shiftkerja pagi terdapat usia terendah yaitu 19 tahun dan usia tertinggi yaitu 37 tahun. Status gizi pada tenaga kerja shift pagi diantara lain yaitu, 28 tenaga kerja status gizi normal, 1 tenaga kerja memiliki status gizi kekurangan berat badan tingkat berat, 5 tenaga kerja memiliki status gizi kelebihan berat badan tingkat berat dan 2 tenaga kerja memiliki status gizi kelebihan berat badan tingkat ringan. Skore perasaan kelelahan kerja pada tenaga kerja shift pagi diantara lain yaitu, 8 tenaga kerja kategori kelelahan sangat ringan, 16 tenaga kerja kategori kelelahan ringan, 8 tenaga kerja kategori kelelahan agak berat, dan 4 tenaga kerja kategori kelelahan berat.

Shiftkerja siang terdapat usia terendah yaitu 18 tahun dan usia tertinggi yaitu 40 tahun. Status gizi pada tenaga kerja shift siang yaitu, 15 tenaga kerja memiliki status gizi normal, 2 tenaga kerja memiliki status gizi kekurangan berat badan tingkat ringan, dan 2 tenaga kerja memiliki status gizi kelebihan berat badan tingkat berat. Skore perasaan kelelahan kerja pada tenaga kerja shift siang antara lain, 8 tenaga kerja mengalami kelelahan sangat ringan, 3 tenaga kerja mengalami kelelahan ringan, dan 8 tenaga kerja mengalami kelelahan agak berat.

Shift kerja malam terdapat usia terendah yaitu 20 tahun dan usia tertinggi yaitu 32 tahun. Status gizi pada tenaga kerja shift malam yaitu, 16 tenaga kerja memiliki status gizi normal, 2 tenaga kerja memiliki status gizi kekurangan berat badan tingkat ringan, dan 1 tenaga kerja memiliki status gizi kelebihan berat badan tingkat ringan. Skore perasaan kelelahan kerja pada tenaga kerja shift malam antara lain, 2 tenaga kerja mengalami kelelahan sangat ringan, 15 tenaga kerja mengalami kelelahan ringan, dan 2 tenaga kerja mengalami kelelahan agak berat.

Tabel 1. Rekapitulasi Hasil Usia Tenaga Kerja Departemen Forming

\begin{tabular}{cccccccr}
\hline N & $\begin{array}{c}\text { Usia } \\
\text { o } \\
\text { Tena } \\
\text { ga } \\
\text { Kerja } \\
\text { (Tahu } \\
\text { n) }\end{array}$ & $\begin{array}{c}\text { Shift } \\
\text { Pagi } \\
\text { (Shif } \\
\text { t 1) }\end{array}$ & $\begin{array}{c}\text { Persent } \\
\text { ase (\%) }\end{array}$ & $\begin{array}{c}\text { Shift } \\
\text { Sian } \\
\text { g } \\
\text { (Shif } \\
t \text { 2) }\end{array}$ & $\begin{array}{c}\text { Jersent } \\
\text { ase (\%) }\end{array}$ & $\begin{array}{c}\text { Shift } \\
\text { Mala } \\
\text { m } \\
\text { (Shif } \\
t ~ 3)\end{array}$ & $\begin{array}{c}\text { Persent } \\
\text { ase (\%) }\end{array}$ \\
\hline 1 & $15-$ & 4 & 11,11 & 4 & 21,05 & 2 & 10,53 \\
& 20 & & & & & & \\
2 & $21-25$ & 11 & 30,55 & 7 & 36,84 & 4 & 21,05 \\
3 & $26-30$ & 14 & 38,89 & 3 & 15,79 & 9 & 47,37 \\
4 & $31-35$ & 6 & 16,67 & 3 & 15,79 & 4 & 21,05 \\
5 & $36-40$ & 1 & 2,78 & 2 & 10,53 & 0 & 0 \\
\hline \multicolumn{2}{l}{ Jumlah } & 36 & 100 & 19 & 100 & 19 & 100 \\
\hline
\end{tabular}

Pada tabel 1 diketahui usia tenaga kerja pada shift pagi dengan jumlah terbanyak yaitu usia 26-30 tahun, pada shift siang usia dengan jumlah terbanyak adalah usia 21-25 tahun dan pada shift malam usia dengan jumlah terbanyak adalah usia 26-30 tahun.

Rata-rata usia tenaga kerja Departemen Forming pada Shift kerja pagi (Shift 1) adalah 26 tahun. Rata-rata usia tenaga kerja Shift Siang (Shift 2) adalah 26 tahun. Rata-rata usia tenaga kerja Shift Malam (Shift 3) adalah 27 tahun. Dan rata-rata usia secara keseluruhan responden pada semua shift kerja adalah 26 tahun.

Dalam penelitian ini tidak ditemukan bahwa semakin tua usia pekerja tingkat kelelahan kerja semakin tinggi, dibuktikan dengan tidak adanya perbedaan 
tingkat kelelahan kerja dengan semakin tuanya usia tenaga kerja. Pada Shift kerja pagi ditemukan 4 tenaga kerja yang mengalami kelelahan berat dengan rentang usia 15-30 tahun, hal tersebut mungkin disebabkan karena status kesehatan dari setiap tenaga kerja yang berbeda serta status gizi yang kurang atau kelebihan berat badan.

Upaya pengendalian kelelahan kerja terkait dengan usia tenaga kerja yaitu dengan memilih usia-usia yang berpeluang baik dalam mengendalikan kelelahan kerja. Pemilihan tenaga kerja yang memiliki semangat kerja yang tinggi dan pendidikan yang memadai sesuai dengan jenis pekerjaannya akan lebih meningkatkan produktivitas kerja.

Tabel 2. Rekapitulasi penilaian status gizi tenaga kerja Departemen Forming

Pada tabel 2 diketahui pada shift kerja pagi, shift kerja siang dan shift kerja malam status gizi tenaga kerja dengan jumlah terbanyak adalah status gizi

\begin{tabular}{|c|c|c|c|c|c|c|c|}
\hline \multirow{2}{*}{$\begin{array}{l}\mathrm{N} \\
\mathrm{O}\end{array}$} & \multirow{2}{*}{$\begin{array}{c}\text { Kategor } \\
\text { i Status } \\
\text { Gizi }\end{array}$} & \multicolumn{6}{|c|}{ Jumlah } \\
\hline & & $\begin{array}{l}\text { Shift } \\
\text { Pagi } \\
\text { (Shif } \\
t 1)\end{array}$ & $\begin{array}{l}\text { Prese } \\
\text { ntase } \\
(\%)\end{array}$ & $\begin{array}{l}\text { Shift } \\
\text { Sian } \\
\text { g } \\
\text { (Shift } \\
2 \text { ) }\end{array}$ & $\begin{array}{l}\text { Persent } \\
\text { ase (\%) }\end{array}$ & $\begin{array}{c}\text { Shift } \\
\text { Malam } \\
\text { (Shift } \\
\text { 3) }\end{array}$ & $\begin{array}{c}\text { Perse } \\
\text { ntase } \\
(\%)\end{array}$ \\
\hline 1 & $\begin{array}{c}\text { KurusB } \\
\text { erat }\end{array}$ & 1 & 2,78 & 0 & 0,00 & 0 & 0,00 \\
\hline 2 & $\begin{array}{c}\text { KurusR } \\
\text { ingan }\end{array}$ & 0 & 0,00 & 2 & 10,53 & 2 & $\begin{array}{r}10,5 \\
3\end{array}$ \\
\hline 3 & Normal & 28 & $\begin{array}{r}77,7 \\
8\end{array}$ & 15 & 78,94 & 16 & $\begin{array}{r}84,2 \\
1\end{array}$ \\
\hline 4 & $\begin{array}{l}\text { Gemuk } \\
\text { Ringan }\end{array}$ & 2 & 5,55 & 0 & 0,00 & 1 & 5,26 \\
\hline 5 & $\begin{array}{c}\text { Gemuk } \\
\text { Berat }\end{array}$ & 5 & $\begin{array}{r}13,8 \\
9\end{array}$ & 2 & 10,53 & 0 & 0,00 \\
\hline & umlah & 36 & 100 & 19 & 100 & 19 & 100 \\
\hline
\end{tabular}

normal. Rata-rata status gizi tenaga kerja pada Shift pagi (Shift 1) adalah 22,07 termasuk dalam kategori status gizi normal. Rata-rata status gizi tenaga kerja shift siang (shift 2) adalah 21,67 termasuk dalam kategori status gizi normal. Rata-rata status gizi tenaga kerja shift malam (shift 3) adalah 20,87 termasuk dalam kategori status gizi normal. Dan rata-rata status gizi keseluruhan tenaga kerja pada semua shift kerja adalah 21,66 termasuk dalam status gizi normal.
Tabel 3. Rekapitulasi penilaian kelelahan kerja tenaga kerja Departemen Forming

\begin{tabular}{|c|c|c|c|c|c|c|c|}
\hline $\mathrm{N}$ & Kategori & \multicolumn{6}{|c|}{ Jumlah } \\
\hline o & $\begin{array}{c}\text { kelelahan } \\
\text { kerja }\end{array}$ & $\begin{array}{c}\text { Shift } \\
\text { Pagi } \\
\text { (Shift } \\
1 \text { ) }\end{array}$ & $\begin{array}{c}\text { Perse } \\
\text { ntase } \\
(\%)\end{array}$ & $\begin{array}{c}\text { Shift } \\
\text { Siang } \\
\text { (Shift } \\
2)\end{array}$ & $\begin{array}{c}\text { Persenta } \\
\text { se (\%) }\end{array}$ & $\begin{array}{l}\text { Shift } \\
\text { Mala } \\
\text { m } \\
\text { (Shift } \\
3)\end{array}$ & $\begin{array}{c}\text { Persenta } \\
\text { se (\%) }\end{array}$ \\
\hline 1 & $\begin{array}{l}\text { Sangat } \\
\text { Ringan }\end{array}$ & 8 & 22,22 & 8 & 42,10 & 2 & 10,52 \\
\hline 2 & Ringan & 16 & 44,45 & 3 & 15,80 & 15 & 78,96 \\
\hline 3 & $\begin{array}{l}\text { Agak } \\
\text { Berat }\end{array}$ & 8 & 22,22 & 8 & 42,10 & 2 & 10,52 \\
\hline 4 & Berat & 4 & 11,11 & 0 & 0 & 0 & 0 \\
\hline 5 & $\begin{array}{c}\text { Sangat } \\
\text { Berat }\end{array}$ & 0 & 0 & 0 & 0 & 0 & 0 \\
\hline 6 & $\begin{array}{c}\text { Amat } \\
\text { Sangat } \\
\text { Berat }\end{array}$ & 0 & 0 & 0 & 0 & 0 & 0 \\
\hline & Jumlah & 36 & 100 & 19 & 100 & 19 & 100 \\
\hline
\end{tabular}

Pada tabel 3 diketahui pada shift pagi kategori perasaan kelelahan kerja dengan jumlah terbanyak adalah kelelahan ringan. Kategori perasaan kelelahan kerja pada shift siang dengan jumlah terbanyak adalah kelelahan sangat ringan dan kelelahan agak berat. Kategori perasaan kelelahan kerja pada shift malam dengan jumlah terbanyak adalah kategori kelelahan ringan.

Rata-rata skore KAUPKK pada tenaga kerja shift pagi Departemen Forming adalah 41,22 termasuk dalam kategori kelelahan ringan. Rata-rata skore KAUPKK pada tenaga kerja shift siang Departemen Forming adalah 38,05 termasuk dalam kategori kelelahan ringan. Dan rata-rata skore KAUPKK pada tenaga kerja shift malam Departemen Forming adalah 38,11 termasuk dalam kategori kelelahan ringan.

Beberapa hal yang perlu mendapat perhatian dan diselenggarakan sebaik-baiknya agar kelelahan kerja dapat dikendalikan adalah sebagai berikut :

1) Lingkungan kerja yang bebas dari zat-zat berbahaya ; pencahayaan yang memadai yang disesuaikan dengan jenis pekerjaan yang dilakukan tenaga kerja; pengaturan udara di tempat kerja dan bebas dari kebisingan dan getaran.

2) Waktu kerja yang berjam-jam harus diselingi oleh istirahat pendek dan istirahat siang yang cukup untuk makan siang dan melaksanakan keperluan pribadi.

3) Kesehatan umum tenaga kerja harus baik dan selalu di monitor; khususnya untuk daerah tropis dimana banyak tenaga kerja yang cenderung mengalami kekurangan gizi dan menderita penyakit yang serius.

4) Disarankan pula agar kegiatan yang menegangkan dan beban kerja yang berat tidak terlalu lama.

5) Jarak tempat tinggal dan tempat kerja diusahakan seminimal mungkin dan bila perlu dicarikan alternatif penyelesaiannya, yaitu berupa pengadaan 
transportasi bagi tenaga kerja dari dan ke tempat kerja.

6) Pembinaan mental para pekerja di perusahaan secara teratur maupun berkala dan khusus perlu dilaksanakan dalam rangka stabilitas tenaga kerja, dan harus ditangani secara baik dilokasi kerja. Fasilitas rekreasi, waktu reaksi dan istirahat direncanakan secara baik dan berkesinambungan. Cuti dan liburan diberikan kepada tenaga kerja dan dilaksanakan sebaik-baiknya dengan memperhatikan faktor fisikopsikososial.

7) Perhatian khusus bagi kelompok tenaga kerja tertentu perlu diberikan, yaitu kepada tenaga kerja usia muda, wanita-wanita yang hamil dan menyusui, tenaga kerja lanjut usia, tenaga kerja yang menjalani kerja shift malam, tenaga kerja yang baru pindah dari bagian lain.

8) Tenaga kerja bebas dari alkohol maupun obat-obatan yang membahayakan serta menimbulkan ketergantungan.

\section{c.Perbedaan perasaan kelelahan kerja pada Shift} Kerja Pagi, Shift Kerja Siang dan Shift Kerja Malam

Dalam penelitian ini, digunakan uji statistik kruskal wallis karena pada tes homogenity nilai sign adalah 0.006 kurang dari dari 5\% maka tidak dapat menggunakan uji statistik Anova. Uji statistik ini bertujuan untuk mengetahui ada tidaknya perbedaan perasaan kelelahan kerja pada shift pagi, shift siang dan shift malam menggunakan aplikasi olah data SPSS.

Uji statistik menunjukan bahwa hasil asympt sign adalah 0.687 sehingga melebihi nilai $\alpha=0.05$ yang sudah ditentukan maka Ho diterima, artinya tidak ada perbedaan perasaan kelelahan kerja pada shift pagi, shift siang dan shift malam.

Tidak adanya perbedaan perasaan kelelahan kerja pada shift pagi, shift siang dan shift malam dikarenakan pengaturan periode istirahat pada saat bekerja sangat baik sehingga ketika tenaga kerja mulai merasakan kelelahan tenaga kerja dapat beristirahat sejenak melakukan peregangan atau penyegaran. Serta pembagian shift kerja yang sesuai dengan menggunakan pergantian sistem kerja tiga rotasi. Pembagian waktu kerja tidak melebihi 8 jam kerja terkecuali apabila terdapat tambahan waktu kerja.

\section{Kesimpulan}

Hasil kuesioner alat ukur perasaan kelelahan kerja pada tenaga kerja Departemen Forming PT. Royal Korindah Purbalingga pada shift pagi adalah 8 tenaga kerja mengalami kelelahan sangat ringan, 16 tenaga kerja mengalami kelelahan ringan, 8 tenaga kerja mengalami kelelahan agak berat, 4 tenaga kerja mengalami kelelahan berat. Pada shift pagi tidak terdapat tenaga kerja yang mengalami kelelahan sangat berat dan kelelahan luar biasa berat.
Hasil kuesioner alat ukur perasaan kelelahan kerja pada tenaga kerja Departemen Forming PT. Royal Korindah Purbalingga pada shift siang adalah 8 tenaga kerja mengalami kelelahan sangat ringan, 3 tenaga kerja mengalami kelelahan ringan dan 8 tenaga kerja mengalami kelelahan agak berat. Pada shift siang tidak terdapat tenaga kerja yang mengalami kelelahan berat, kelelahan sangat berat dan kelelahan luar biasa berat.

Hasil kuesioner alat ukur perasaan kelelahan kerja pada tenaga kerja Departemen Forming PT. Royal Korindah Purbalingga pada shift malam adalah 2 tenaga kerja mengalami kelelahan sangat ringan, 15 tenaga kerja mengalami kelelahan ringan dan 2 tenaga kerja mengalami kelelahan agak berat. Pada shift malam tidak terdapat tenaga kerja yang mengalami kelelahan berat, kelelahan sangat berat dan kelelahan luar biasa berat.

Karakteristik tenaga kerja berdasarkan jenis kelamin berjumlah 74 tenaga kerja laki-laki dengan persentase $100 \%$. Rata-rata usia tenaga kerja pada shift pagi 26 tahun, pada shift siang 26 tahun dan pada shift malam 27 tahun. Rata-rata status gizi pada shift pagi adalah 22,07 termasuk dalam kategori status gizi normal, pada shift siang 21,67 termasuk dalam kategori status gizi normal dan pada shift malam 20,87 termasuk dalam kategori status gizi normal. Waktu kerja shift pagi 07.00-15.00 WIB, waktu kerja shift siang 15.00-23.00 WIB dan waktu kerja shift malam 23.00-07.00 WIB.

Berdasarkan uji statistik menggunakan uji kruskal wallis tentang perbedaan perasaan kelelahan kerja pada shift pagi, shift siang dan shift malam diperoleh nilai assympt sig. 0,687 lebih besar dari nilai $\alpha$ $=0.05$ dinyatakan bahwa tidak ada perbedaan perasaan kelelahan kerja pada shift pagi, shift siang dan shift malam.

\section{Ucapan Terimakasih}

Dalam menyelesaikan karya tulis ilmiah ini penulis banyak mendapat bantuan baik materiil maupun moril dari berbagai pihak, untuk itu penulis mengucapkan terimakasih kepada Bapak Yulianto, BE., S.Pd., M.Kes selaku pembimbing penelitian. Bapak, ibu, Tata Fitroh, Paman Anton dan teman-teman saya yang telah memberikan dukungan.

\section{Daftar Pustaka}

Adriana Pusparini, A.M. Sugeng Budiono, Aztanti Srie Ramandhani, Benny L. Priatna, Didi Sugandi, Eddy Charles, Ferry Benzon, Raswin Rusmana, Murni Siswati, Niken Diana Habsari, Odjak Turnip, Iyus Hidayat, R.M.S. Jusuf, Siti Heryuni, Slamet Ichsan, Sunarsih, Waluyo, 2009, Bunga Rampai Hiperkes \& KK, Semarang: Badan Penerbit Universitas Diponegoro.

Aziz Alimul Hidayat, 2010, Metode Penelitian Kebidanan Teknik Analisis Data, Jakarta: Salemba Medika. 
Departemen Kesehatan Republik Indonesia, 2009, Undang-Undang Republik Indonesia No. 36 ahun 2009 Tentang Kesehatan, Jakarta: Depkes RI.

Djamaluddin Ramlan, 2006, Dasar-dasar Kesehatan Kerja, Purwokerto: JKL Purwokerto.

Lientje Setyawati, 2011, Selintas tentang Kelelahan Kerja, Yogyakarta: Amara Books.

Presiden Republik Indonesia, 2003, Undang-Undang No. 13 tahun 2003 tentang Ketenagakerjaan, Jakarta: Pemerintah RI.

Soekidjo Notoatmodjo, 2002, Metodologi Penelitian Kesehatan, Jakarta: Rineka Cipta.
Sugeng Budiono, 2003, Bunga Rampai Hyperkes dan $K K$, Semarang : BP UNDIP

Suma'mur, 2014, Higiene Perusahaan dan Kesehatan Kerja (Hiperkes), Jakarta: CV Sagung Seto.

Tarwaka, Solichul Ha. Bakri, Lilik Sudiajeng, 2004, Ergonomi untuk Keselamatan, Kesehatan Kerja dan Produktivitas, Surakarta: Uniba Press. 